This is a self-archived - parallel published version of this article in the publication archive of the University of Vaasa. It might differ from the original.

\title{
Demand response method for smart microgrids considering high renewable energies penetration
}

Author(s): Hakimi, Seyed Mehdi; Hasankhani, Arezoo; Shafie-khah, Miadreza, Catalãoe, João P.S.

Title: $\quad$ Demand response method for smart microgrids considering high renewable energies penetration

Year: $\quad 2020$

Version: Final draft (post print, aam. accepted manuscript)

Copyright C)2020 Elsevier Inc. This manuscript version is made available under the Creative Commons Attribution-NonCommercial-NoDerivatives 4.0 International (CC BY-NC-ND 4.0) license, https:// creativecommons.org/licenses/by-nc-nd/4.o/

Please cite the original version:

Hakimi, S.M., Hasankhani, A., Shafie-khah, M., Catalãoe, J.P.S., (2020). Demand response method for smart microgrids considering high renewable energies penetration. Sustainable energy, grids and networks 21. https://doi.org/10.1016/j.segan.2020.100325 


\title{
Demand Response Method for Smart Microgrids Considering High Renewable Energies Penetration
}

\author{
Seyed Mehdi Hakimi ${ }^{\mathrm{a}, \mathrm{b}}$, Arezoo Hasankhani ${ }^{\mathrm{c}}$, Miadreza Shafie-khah ${ }^{\mathrm{d}}$, João P. S. Catalão ${ }^{\mathrm{e}}$ \\ ${ }^{a}$ Electrical Engineering Department, Damavand Branch, Islamic Azad University, Damavand, Iran \\ ${ }^{b}$ Renewable Energy Research Center, Damavand Branch, Islamic Azad University, Damavand, Iran \\ ${ }^{c}$ Department of Computer and Electrical Engineering and Computer Science, Florida Atlantic University, Florida, U.S. \\ ${ }^{d}$ School of Technology and Innovations, University of Vaasa, 65200 Vaasa, Finland \\ ${ }^{e}$ Faculty of Engineering of the University of Porto and INESC TEC, Porto 4200-465, Portugal \\ * corresponding author (catalao@fe.up.pt) at INESC TEC and the Faculty of Engineering of University of Porto.
}

\begin{abstract}
One of the most important reasons of smart grids (SGs) is renewable energies (REs) increase and demand response (DR). Present methods are not practical in the case of high REs presence in SGs and should be revised. The flexibility of production is low in SGs with high REs penetration, and loads should follow the production. The increase in the domestic controllable loads (DCLs) flexibility compensates the low flexibility in production. As a result, DR is essential in SGs with high share of REs. This study presents a new method for DR with high REs penetration. Also, a new formulation for electrical appliances is provided in this study, including washing machine, dish washer and heating/cooling system. In the proposed method, the RE resources produced power is considered in addition to loads condition. The controllable loads are transferred to the time when the difference between load and RE generated power is maximum (considering the consumers' welfare). The results show that applying this method will increase the flexibility of consumption and REs penetration in SGs. The study is performed for the Ekbatan residential complex that includes three smart microgrids and a $63 / 20 \mathrm{kV}$ substation in Tehran, Iran.
\end{abstract}

Keywords: smart grids; renewable energies; demand response; flexibility; domestic controllable loads. 


\section{Introduction}

In order to solve environmental problems, energy crisis, high penetration of renewable energy (RE) resources and improving reliability of power system, demand side partnership is unavoidable and necessary to realize smart microgrids' goals. Smart grids provide conditions of bi-directional connection and smart demand response (DR). In non-smart grids, electric company usually controls the demand of consumers, and only large consumers can participate in DR programs. In condition that smart grids give the opportunity not only to large consumers but also small users, so DR of residential users is essential in smart grids.

One of the smart grids' objectives is reaching more share of RE resources in grids. High RE resources in grids decreases the flexibility of generation due to stochastic nature of these resources, so applying novel DR methods is necessary. Present DR methods aren't applicable in case of high penetration of RE resources. In this kind of grids, the consumers' welfare and generation conditions should be considered simultaneously to make a balance between demand and generation.

Since the main object of this study is the implementation of DR in a smart microgrid, the behaviour of controllable loads should be modelled. Initially, the behaviour of controllable high power domestic loads is modelled, and it is assumed that the studied microgrids are smart. After modeling of stochastic behavior of controllable residential load, the novel method will be investigated to reach the goal of DR for domestic loads.

The Ekbatan residential complex is considered as the research case study. Ekbatan has three separate sets of buildings called respectively phase A, B and C as smart microgrids (Figure 1). The smart microgrid No.1 consists of photovoltaic panel, battery, wind turbine and controllable loads (washing machine, dishwasher, heating/cooling system) and uncontrollable loads. The schematic of this microgrid is depicted in Figure 2. Parking of each block is located at that block in the smart microgrids. Furthermore, the charge/discharge management of plug-in electric vehicles has effects only on that block. Any block of the Ekbatan complex is assumed as a bus in this paper.

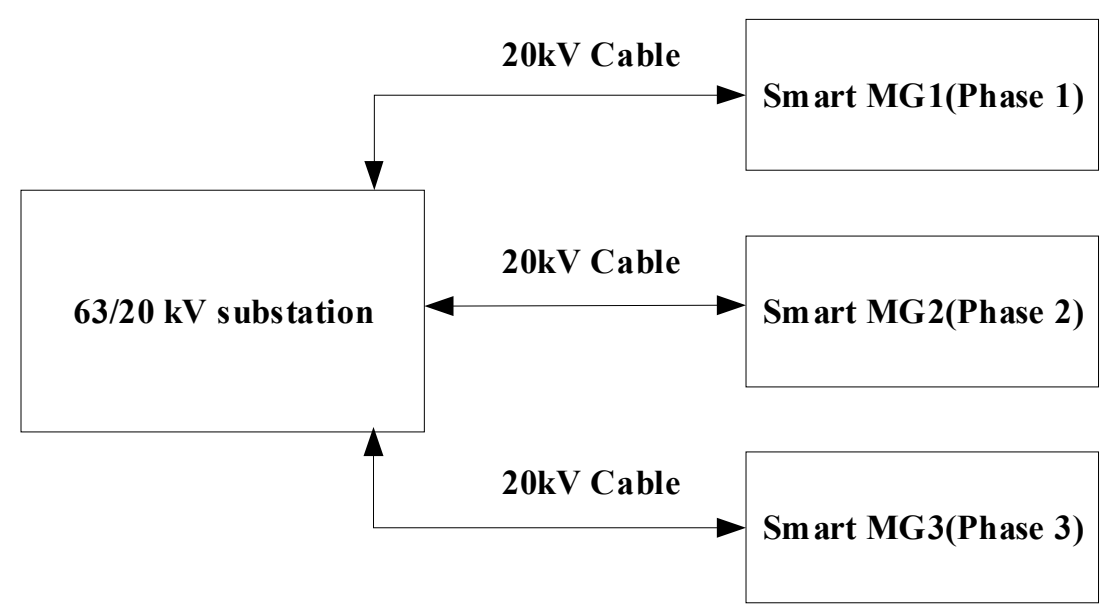

Fig. 1. The diagram of grid 


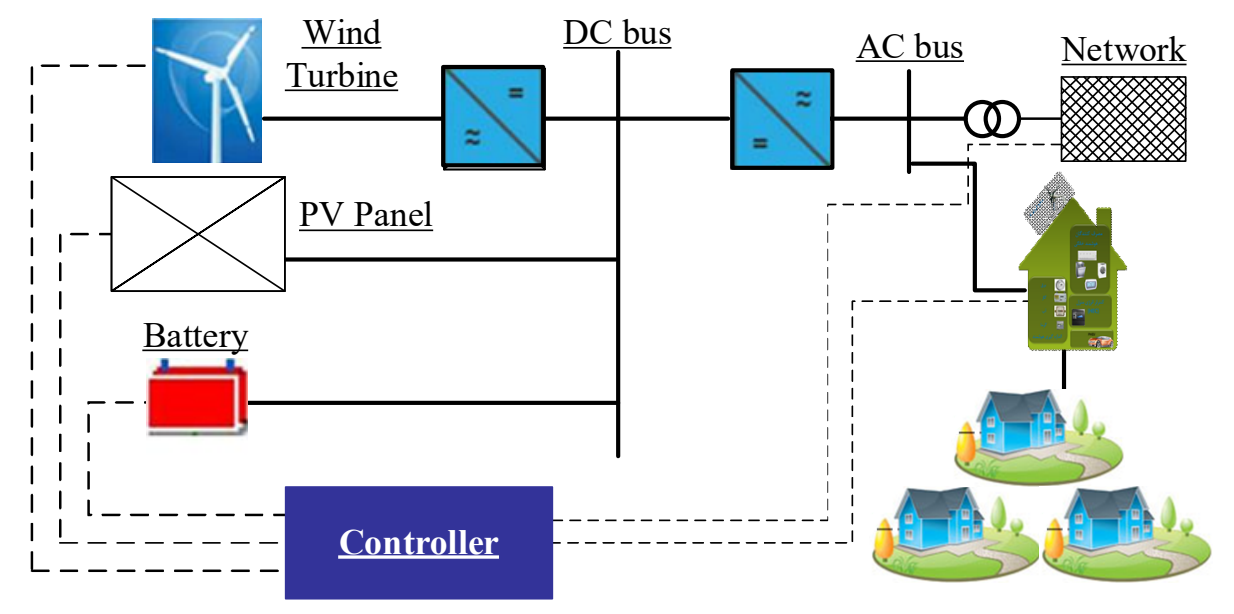

Fig. 2. The schematic of microgrid

In [1], a detailed review of demand side management, DR programs, distributed generation considering RE resources as the main focus is presented. A stochastic programming model was investigated in order to minimize the operating costs considering RE resources by the multi-objective particle swarm optimization method. The uncertainty of solar and wind sources was assumed with the participation of different residential, commercial and industrial consumers [2]. In [3], the importance of storage, DR, electric vehicles, and transmission expansion was studied in reducing the uncertainty of RE resources. In this study, a new scenario-based electricity system model called SILVER was designed as a flexible tool to test different constraints including curtailment rates, grid interconnectivity, system cost and emission. In [4] and [5], the effect of domestic loads and electric vehicles on smart microgrid was studied.

A review paper [6] discussed different topics related to storage demand, flexibility requirements, and resource potential in case of growing variable RE in future energy systems. The authors of [7] presented an approximate dynamic programming (ADP) in order to test real data set related to applying stochastic RE resources and energy storage systems. In [8], a distributed DR problem by low-cost wireless network was investigated in a neighbourhood with a large number of load costumers and RE resources. The real solar power data was applied in addition to rolling-window-based model-predictive control method and simple load and RE system forecasting method in this paper. The solar energy using a hybrid model consisting of neural networks and wavelet transform was forecasted, and a pumped hydro storage application and DR program were integrated to analyse the performance of photovoltaic system [9].

In [10], the political and technical necessities toward applying RE system as main sources in power systems were introduced. In this paper, the near term and mid-term aim to increase the flexibility of power system while long-term actions focus on tackling the fluctuation of RE systems. The role of heating/cooling system using an active controller in SGs with high penetration of RE resources was investigated. The objective function in this paper was minimizing the overall cost and the size of smart microgrid units. The stochastic modeling of the washing machine was extracted using the multivariable probability distribution function, and Monte Carlo technique was applied to generate different load profiles' sample. 
In [11], home energy management was done considering the dynamic pricing schemes, small RE resources and electric vehicles using mixed integer linear programming. In [12] and [13], the DR effect on load profile and voltage profile and demand peaks was studied. In [14], [15] and [16], the protection methods and barriers in microgrids with RE resources were proposed in grid-connected condition. In [17], authors presented a DR scheduling model in order to reduce the cost of user's electricity consumption, peak load and peak-valley difference of residential loads. In [18], the factors that help retail consumers for participating in DR program and time of use pricing were recognized. In [19], a two-stage robust optimization model was suggested to solve the energy cost minimization problem for SGs in a condition that each consumer was equipped with the photovoltaic system and a battery. The problem of eliminating overloading in transmission lines, generation and load shedding cost minimization and social welfare maximization was addressed in [20] by a multi-objective optimization problem. The genetic algorithm and two-point estimate method were applied in order to minimize the adjustment cost in a hybrid system including wind, solar, and conventional thermal generators [21].

In [22], the new DR technique called weighting queuing algorithm was developed to control the thermostatically appliances like an air conditioner in order to increase the share of RE resources. In [23], the optimization problem was investigated for residential SG DR with RE resources considering the consumers' convenience. In this paper, real-time pricing and progressive pricing were solved by convex programming and heuristic algorithm. A practical home energy management system with RE, energy storage system and plug-in electric vehicles was introduced in [24]. In the studied paper, the optimization problem with goals of minimizing the electricity purchase and maximizing the RE share was solved by the combinations of genetic algorithm and multi-constrained integer programming method. In [25], the heating system has been used in order to absorb the extra energy of RE resources and reduce the cost of electricity. In [26], the impact of energy storage, RE systems and DR program have been studied with two-period stochastic programming method. In these studies, only some types of residential appliances have been considered. However, we model the major residential appliances including washing machine, dishwasher and heating/cooling system in this study. It is also important to mention that we consider high penetration of RE in our study, which increases the uncertainties in power supply.

In [27], the capacity credit of RE resources considering the DR program was assessed by sequential Monte Carlo method. In [28], a two-stage stochastic model was presented for systems with a large share of RE resources and electric vehicles in Portugal. In [29], a new dynamic demand control was developed to mitigate the frequency deviations related to intermittent RE generation by electric vehicles. The role of ice-thermal storage as a smart load in eliminating the voltage disturbance in case of RE resources high penetration was demonstrated in [30]. In [31], the DR program and energy management in presence of RE resources, shiftable and nonshiftable loads have been investigated on electricity cost minimization. The multi-objective problem for minimizing both total cost and costumers' inconvenience has been studied in order to reduce the peak to average ratio [32]. 
Some studies have reviewed the DR management in SG. In [33], the real time DR method has been investigated, and the proposed method has been tested on testbed at the Singapore university of technology and design in order to observe the consumer's behavior. In another study [34], the DR management scheme has been proposed for two different types of costumers including green savvy and green aware plan. The costumers have been classified into two types of non-green comfort seeking behavior and green incentive seeking behavior based on factors that affect the DR management program [35]. In [36], the response time and behavior of residential consumers have been studied considering internet of things integration to smart homes. Two different methods including constant deviation plans and proportional deviation plans have been applied in order to peak load reduction [37].

According to the previously described literature review, the contribution of the study can be listed as follows:

- Investigation of a new method to implement DR in the condition that RE resource penetration is high, which increases the correlation between generations and loads.

- Considering the DR of different types of controllable loads (washing machine, dish washer, heating/cooling system) at the same time.

- Developing a new formulation for electrical appliances, including washing machine, dish washer and heating/cooling system.

The rest of the paper is organized as follows. Section 2 provides the details of the modeling of controllable high power domestic appliances. Section 3 addresses the cost of smart homes' appliances. Section 4 is devoted to simulation and result discussion. Finally, section 5 provides some relevant conclusions.

\section{Modelling of controllable high power domestic appliances in smart microgrids}

In the presented method, load condition and power generation of RE resources are supposed simultaneously, which leads to the maximum use of produced power, the balance between generation and consumption, cost reduction, reducing size, and improving reliability. In this study, the load is calculated by IEEE standard, which is based on p.u. [38]. The load profile is calculated by multiplying peak load to IEEE standard profile.

\subsection{Washing machine}

The washing machine's start time can have 3-hour maximum shift (considering the consumer's welfare extracted of questionnaires). The maximum time for load shifting is chosen based on survey from residential consumers. In this questionnaire, most of residential consumers (83\%) intends to use smart washing machine and shift their use time. The maximum time for load shifting is shown in Figure 3. As it is shown in this Figure, most of consumers (46\%) choose 3-hour time shift, which is used in our study. 


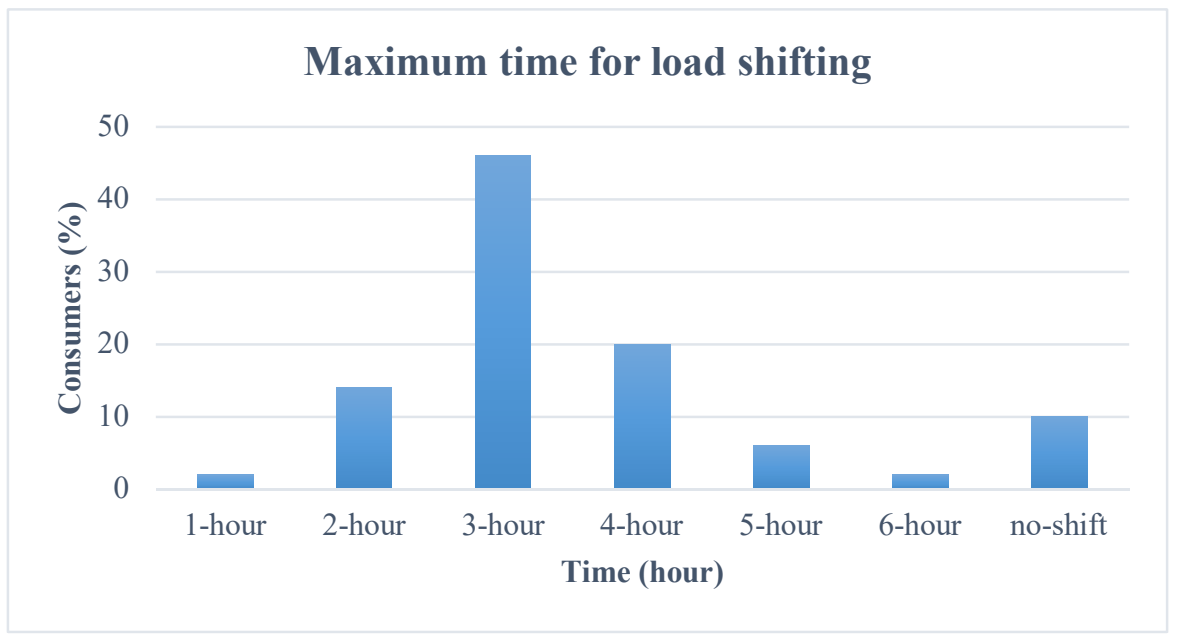

Fig. 3. Maximum time for load shifting (washing machine)

Time steps for washing machine shifting are supposed to be 15 minutes. In the 3-hour time interval, the surplus power (the difference between produced power by RE resources and load) and peak load of the washing machine are calculated. The washing machine's profile is shifted to the hour when the difference is maximum. The surplus power refers to the alternation between the generated power of RE resources and microgrid load.

$$
\begin{gathered}
P_{\text {surplus }}(t)=P_{R E N}(t)-P_{\text {base }}(t) \\
P_{R E N}(t)=P_{W T}(t)+P_{P V} \\
\Delta=\left(P_{\text {surplus }_{n}}\left(\frac{t}{4}+h\right)-W M_{\max } \mid \begin{array}{c}
t=t_{\text {max }} \\
t=0
\end{array}\right. \\
\Delta_{\max }=\Delta \mid t=t_{n h} \\
0 \leq h \leq 8760 \\
0 \leq t \leq t_{\max }
\end{gathered}
$$

The objective is determining the maximum amount of $\Delta$. In another word, the goal is determining the best time shifting for washing machine $\mathrm{n}$, which should start at $\mathrm{h}\left(\mathrm{t}_{\mathrm{nh}}\right) . \mathrm{t}$ is time shift in washing machine's start time, and $\mathrm{t}_{\text {max }}$ is the maximum acceptable time for customers. $\mathrm{WM}_{\max }$ refers to maximum consumption of washing machine, and $\mathrm{n}$ shows the number of washing machines which start at $\mathrm{h}$. After finding the best start time for washing machine, it is shifted to that time. New surplus power is calculated based on (7).

$$
\begin{gathered}
P_{\text {surplus }_{(W M) 1}}(t)=\left(P_{\text {surplus }}(t)-P_{(W M) 1-\text { manage })}\right. \\
P_{\text {Surplus }_{(W M) n_{W M}}}(t) \\
=\left(P_{\text {surplus }_{(W M) n-1} \text { MM }}(t)\right. \\
\left.-P_{(W M) n_{W M}-\text { manage }}(t)\right) \\
2 \leq n_{W M} \leq n_{W M(\max )}(t)
\end{gathered}
$$


Where $\mathrm{P}_{(\mathrm{WM}) 1-\text { manage })}(\mathrm{t})$ is the consumption power related to the first washing machine after DR, which starts at $t$.

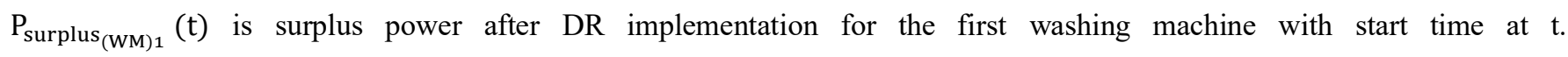
$\mathrm{P}_{(\mathrm{WM}) \mathrm{n}_{\mathrm{WM}}-\text { manage }}(\mathrm{t})$ and $\mathrm{P}_{\text {surplus }}(\mathrm{WM}) \mathrm{n}_{\mathrm{WM}}(\mathrm{t})$ are related to washing machine with the similar definition. $\mathrm{n}_{W M}(\max )(\mathrm{t})$ determines the maximum number of washing machines which start at $\mathrm{t}$.

This method is implemented for other washing machines which start at $\mathrm{h}$ th hour, respectively. Then, it is applied for other hours, and new start time are specified. The new microgrid's load profile is calculated by (10).

$$
\begin{aligned}
P_{\text {load-manage }(W M)}(t) & \\
= & P_{\text {base }}(t) \\
& +P_{(\text {connect at } t)(W M)}(t) \\
& -P_{(\text {disconnect at } t)(W M)}(t)
\end{aligned}
$$

Where $\mathrm{P}_{\text {load-manage }(\mathrm{WM})}(\mathrm{t})$ indicates the new load profile at $\mathrm{t}$ after applying the consumption management on the washing machine. $\mathrm{P}_{(\text {connect at } t)(W M)}$ shows the amount of power of washing machine shifted to $t$ while $\mathrm{P}_{(\text {disconnect at } t)(W M)}$ determines the amount of power shifted from $t$ to another time.

$\mathrm{P}_{(\text {connect at } \mathrm{t})(\mathrm{WM})}$ consists of two different parts:

- $\quad$ Start time of considered appliance (washing machine) is shifted to t.

- Start time of appliance (washing machine) is shifted to previous time from $t$, which leads to an increase in power at $\mathrm{t}$.

$P_{(\text {connect at } t)(W M)}$ is expressed as follows:

$$
\begin{aligned}
P_{(\text {connect at } t)(W M)} & (t) \\
& =\sum_{i=1}^{\mathrm{t}-1} N_{\mathrm{it}} \times P(1) \\
& +\sum_{\mathrm{i}=1}^{\mathrm{t}-\mathrm{m}} \sum_{\mathrm{m}=1}^{\mathrm{L}-1} N_{\mathrm{i}(\mathrm{t}-\mathrm{m})} \times P(\mathrm{~m}+1)
\end{aligned}
$$

Where $\mathrm{N}_{\text {it }}$ shows the number of washing machine shifted from i to t. $\mathrm{P}(1)$ is the amount of power consumption during period $(1)$, and $\mathrm{P}(\mathrm{m}+1)$ is the quantity of power consumption during period $(\mathrm{m}+1)$. L determines the whole time interval related to washing machine's consumption.

$\mathrm{P}_{\text {(disconnect at } \mathrm{t})(\mathrm{WM})}$ can be calculated by equation 


$$
\begin{aligned}
P_{(\text {disconnect at } t)(W M)}(t) & \\
= & \sum_{s=t+1}^{t+h_{k}} N_{t s} \times P(1) \\
& +\sum_{s=t+1}^{t-m+h_{k}} \sum_{m=1}^{L-1} N_{(t-m) s} \times P(m+1)
\end{aligned}
$$

Where $\mathrm{N}_{\mathrm{ts}}$ specifies the number of washing machine shifted from $\mathrm{t}$ to $\mathrm{s}$, and $\mathrm{N}_{(\mathrm{t}-\mathrm{m}) \mathrm{s}}$ similarly shows the number of washing machine shifted from (t-m) to $\mathrm{s} . \mathrm{hk}$ is the maximum acceptable delay related to washing machine's start time.

\subsection{Dishwasher}

The proposed method for dishwasher DR is similar to the washing machine, only start time can be shifted utmost 6 hours (considering consumers' comfort extracted of questionnaires), and there is no limitation related to dishwasher after $10 \mathrm{pm}$ (which is limited for washing machine). The maximum time for load shifting is chosen based on questionnaire from residential consumers, and most of them (37\%) agree to 6-hour time shifting, so 6-hour is chosen for load shifting. The results of questionnaire for 7 different load shifting states are shown in Figure 4.

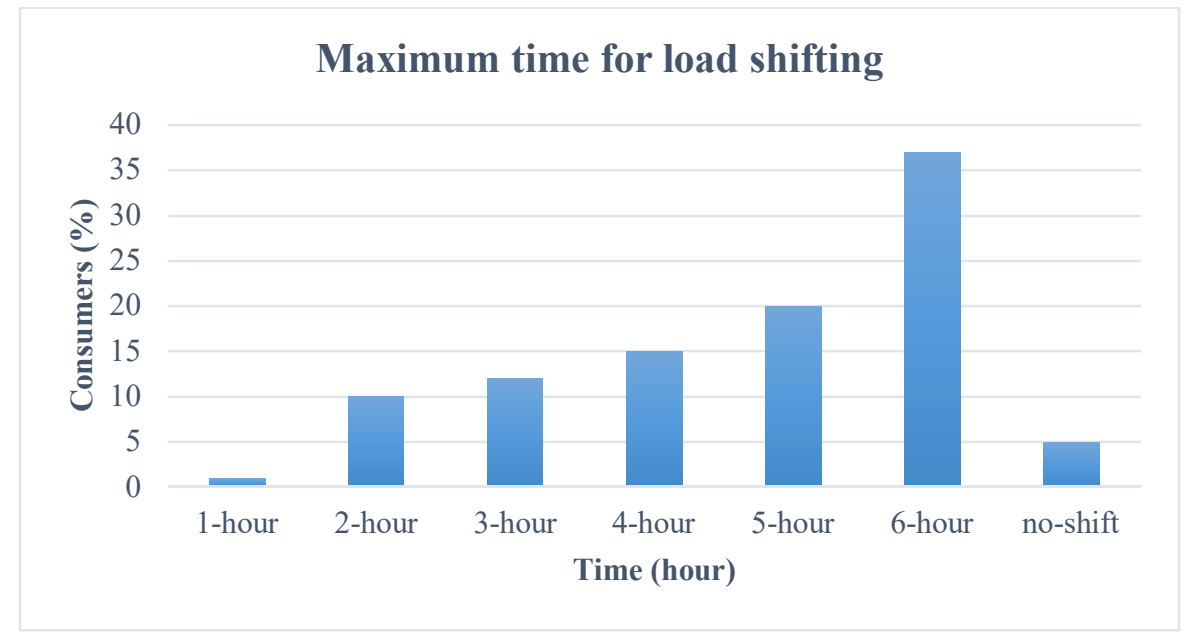

Fig. 4. Maximum time for load shifting (dishwasher)

Similar to the washing machine, the optimal shift time for the dishwasher is obtained. It should be noted that the dish washer's surplus power is determined as follows.

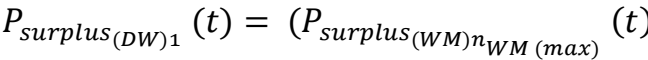

$$
\begin{aligned}
& \left.-P_{(D W) 1-m a n a g e)}(t)\right) \\
& P_{\text {surplus }_{(D W) n_{D W}}}(t) \\
& =\left(P_{\text {surplus }_{(D W) n-1}{ }_{D W}}(t)\right. \\
& \left.-P_{(D W) n_{D W}-\text { manage }}(t)\right)
\end{aligned}
$$




$$
2 \leq n_{D W} \leq n_{D W(\max )}(\mathrm{t})
$$

Where $\mathrm{P}_{(\mathrm{DW}) 1-\text { manage })}(\mathrm{t})$ and $\mathrm{P}_{(\mathrm{DW}) \mathrm{n}_{\mathrm{DW}}-\text { manage }}$ show the first and the $\mathrm{n}$ th dish washer's consumption power after DR implementation with start time at $t$, respectively. $P_{\operatorname{surplus}_{(\mathrm{WM}) n_{W M}(\max )}}(t), \mathrm{P}_{\text {surplus }_{(\mathrm{DW}) 1}}(\mathrm{t})$, and $\mathrm{P}_{\text {surplus }_{(\mathrm{DW}) \mathrm{n}-1 \mathrm{DW}}}(\mathrm{t})$ indicate the surplus power after applying DR method for the last, the first, and the $n-1$ th washing machine with start time at $\mathrm{t}$, respectively. $\mathrm{n}_{\mathrm{DW}(\max )}(\mathrm{t})$ determines the maximum number of dishwashers which start at $\mathrm{t}$.

So the new load profile can be defined as follows.

$$
\begin{aligned}
P_{\text {load-manage }(W M, D W)}(t) \\
\quad=P_{\text {base }}(t) \\
+P_{(\text {connect at } t)(W M, D W)}(t) \\
-P_{(\text {disconnect at } t)(W M, D W)}(t)
\end{aligned}
$$

Where $P_{\text {load-manage }(W M, D W)}(t)$ represents the new load profile at $t$ after applying consumption management on washing machines and dishwashers. $P_{(\text {connect at } t)(\mathrm{WM}, \mathrm{DW})}$ is the amount of washing machine and dish washer's power shifted to $t$. $\left.P_{(\text {disconnect at } t)(W M, D W}\right)$ represents the amount of power shifted from $t$ to another time.

$\mathrm{P}_{(\text {connect at } t)(W M, D W)}(t)$ contains two parts:

- Start time related to the supposed appliance (washing machine and dishwasher) is shifted to t.

- Start time related to the appliance (washing machine and dishwasher) is shifted to time before $t$, and raises the amount of power at $\mathrm{t}$.

$\mathrm{P}_{\text {(connect at } \mathrm{t})(\mathrm{WM}, \mathrm{DW})}(\mathrm{t})$ can be calculated by (17).

$$
\begin{aligned}
P_{(\text {connect at } t)(W M, D W)}(t) & \\
= & \sum_{i=1}^{t-1} \sum_{k=1}^{D} N_{k i t} \times P(1)_{k} \\
& +\sum_{i=1}^{t-m} \sum_{m=1}^{L-1} \sum_{k=1}^{D} N_{k i(t-m)} \\
& \times P(m+1)_{k}
\end{aligned}
$$

Where $\mathrm{N}_{\mathrm{kit}}$ is the number of appliance type $\mathrm{k}$ (washing machine or dishwasher) shifted from $\mathrm{i}$ to $\mathrm{t}$. $\mathrm{D}$ is the number of appliances which can be shifted, and it equals to two related to the washing machine and dishwasher. $\mathrm{P}(1)_{\mathrm{k}}$ determines the amount of consumption power related to an appliance of type $\mathrm{k}$ (washing machine or dish washer) during period $(\mathrm{m}+1)$. $\mathrm{L}$ is the whole time interval related to the appliance of type $\mathrm{k}$.

$\mathrm{P}_{\text {(disconnect at } \mathrm{t})(\mathrm{WM}, \mathrm{DW})}$ is utilized as below. 


$$
\begin{aligned}
P_{(\text {disconnect at } t)(W M, D W)}(t) & \\
= & \sum_{s=t+1}^{t+h_{k}} \sum_{k=1}^{D} N_{k t s} \times P(1)_{k} \\
& +\sum_{s=t+1}^{t-m+h_{k}} \sum_{m=1}^{L-1} \sum_{k=1}^{D} N_{k(t-m) s} \\
& \times P(m+1)_{k}
\end{aligned}
$$

Where $\mathrm{N}_{\mathrm{kts}}$ and $\mathrm{N}_{\mathrm{k}(\mathrm{t}-\mathrm{m}) \mathrm{s}}$ are the number of appliances of type $\mathrm{k}$ (washing machine or dishwasher) shifted from $\mathrm{t}$ and ( $\mathrm{t}-\mathrm{m}$ ) to $\mathrm{s}$, respectively. hk is the maximum acceptable delay of the washing machine or dishwasher.

The total microgrid's load before applying load management on dishwasher and washing machine is defined as follows.

$$
\begin{aligned}
P_{\text {load-unmanage }(} & \text { WM }, \mathrm{DW}) \\
& =P_{\text {base }}(t)+P_{W M \text { unmanage }}(t) \\
& +P_{D W \text { unmanage }}(t)
\end{aligned}
$$

\subsection{Heating/cooling system}

Heating/cooling system plays an important role in energy consumption. As a result, controlling these loads can be suitable in case of optimal use of RE resources. In this paper, active controllers are applied for controlling them. To implement the model, the presented method in [2] is adopted, and the details of the method are not described in this paper.

In this method, applying the active controllers, consumers set the desired temperature. Then, active controller considering set point and the difference between the generated power of RE resources and consumption power calculates the indoor temperature and the amount of power of heating/cooling system. This temperature is called real temperature

$$
\begin{gathered}
P_{\text {load-manage }(W M, D W, H V A C)}(t) \\
=P_{\text {load-manage }(W M, D W)}(t) \\
+P_{H V A C-\text { manage }}(t)
\end{gathered}
$$

Where $\mathrm{P}_{\text {load-manage (WM,DW,HVAC) }}(\mathrm{t})$ shows the new load profile at $\mathrm{t}$ when the load management is applied on the washing machine, dishwasher, and heating/cooling system. The surplus power is defined as follows to manage the consumption of heating/cooling system.

$$
\begin{aligned}
P_{\text {surplus }_{(H V A C) 1}}(t) & \\
= & \left(P_{\text {surplus }_{(D W) n_{D W}(\text { max })}}(t)\right. \\
& \left.-P_{(\text {HVAC }) 1-\text { manage })}\right)
\end{aligned}
$$




$$
\begin{aligned}
P_{\text {surplus }_{(H V A C) n_{H V A C}}} & \mathrm{t}) \\
= & \left(P_{\text {surplus }_{(H V A C) n-1} \text { HVAC }}(\mathrm{t})\right. \\
& \left.-P_{(\mathrm{HVAC}) n_{H V A C}-\text { manage }}\right) \\
2 \leq n_{H V A C} & \leq n_{H V A C \text { (max })}(t)
\end{aligned}
$$

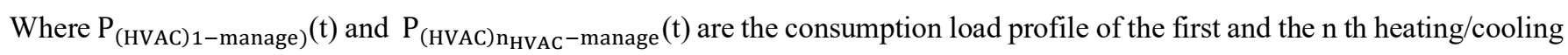

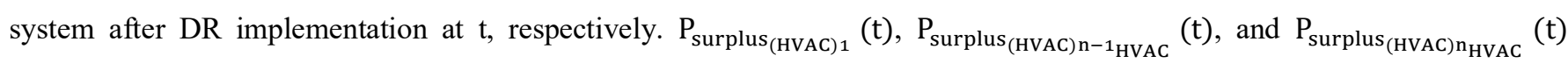
determine the amount of surplus power of the first, the (n-1) th, and the $\mathrm{n}$ th heating/cooling system after applying DR method, which start at t. $P_{\text {surplus }}(\mathrm{DW}) \mathrm{n}_{\mathrm{DW}(\max )}$ shows the amount of surplus power after applying DR method for the $\mathrm{n}$ th dishwasher at $\mathrm{t}$. $\mathrm{n}_{\text {HVAC (max) }}$ indicates the maximum number of heating/cooling systems which start at $\mathrm{t}$.

\section{Appliances}

It is assumed that the studied homes in Ekbatan complex and the controllable loads (smart washing machine, smart dishwasher, and smart cooling/heating systems) are smart, for which the DR are implemented in the presence of RE resources. In order to the application of smart appliances considering DR requirements, two other costs should be supposed compared to non-smart ones:

- The cost of smart appliances

- $\quad$ The incentives related to participation in DR programs, which are explained as follows.

\section{1. - The cost of smart appliances}

The cost modeling of smart appliances is explained in detail in [39], which is briefly discussed here. The cost for shifting smart appliances is seen as incentives in objective function, which is shown in Equation 24 and Equation 25.

\subsubsection{Cost of communication modules}

The smart appliances should be equipped with a communication module to be connected to the smart meters which can be implemented either wireless or wired. It is forecasted that the commercialization of smart appliances leads to cost of $4.4 \$$ for each communication module [39].

\subsubsection{Cost of communication in smart home}

Communication between smart meters and smart appliances plays an important role in the smart home, which can be connected by PLC or have direct access to the internet. It doesn't need extra wiring. It is assumed that the smart meters and internet are wireless, so communication is free in the smart home.

\subsubsection{Extra cost for appliances for getting ready to start}

Smart appliances should be ready to respond in a condition that there is a signal from smart meters, which increases the electricity consumption between $0.1 \%-2 \%$ [39]. It leads to an increase about $1.5 \$$ per any appliances annually. 


\subsubsection{Cost of consumption management}

Consumption management programs participation isn't free, and it costs about 10.2-21.3 \$ for participants [39].

\subsection{Incentives for smart appliances}

There is no motivation for smart appliances because of their excessive costs, which means that incentives should be put to encourage the consumers. It can compensate the extra price of smart appliances because of above factors. The considered incentives for encouraging consumers to increase the DR acceptance are as follows:

\subsubsection{Incentives subject to appliance's availability}

In this condition, the smart appliances are encouraged because of their availability in the specific time interval. For instance, consumer puts his/her dishes in the dishwasher and sets the maximum acceptable delay, so the dishwasher goes into ready to start mode. Participants should be paid in this situation whether start time is shifted or not.

\subsubsection{Incentives subject to execution of DR program}

If smart appliances change their start time based on received signals from smart meters, they should be paid because of execution of DR program. In this study, the annual incentives related to smart appliances are calculated as follows:

$$
\begin{aligned}
& \text { Incentive }-a v l_{\mathrm{i}}=\frac{1}{5} \frac{\mathrm{SAC}_{\mathrm{i}}}{\mathrm{N}(\text { start }- \text { ave })_{\mathrm{i}}} \times \mathrm{N}(\mathrm{avl})_{\mathrm{i}} \\
& \text { Incentive }- \text { shift } t_{\mathrm{i}}=\frac{\mathrm{SAC}_{\mathrm{i}}}{\mathrm{N}(\text { start }-\mathrm{ave})_{\mathrm{i}}} \times \mathrm{N}(\text { shift })_{\mathrm{i}}
\end{aligned}
$$

Where SACi is the extra cost should be paid for appliance i, N (start - ave) $)_{i}$ is the average number of uses of appliance $i$, and $\mathrm{N}(\mathrm{avl})_{\mathrm{i}}$ is the number of being available of appliance $\mathrm{i}$, andN (shift $)_{\mathrm{i}}$ is the number of shifting of appliance $\mathrm{i}$ annually.

\section{Simulation and result discussion}

In this section, the simulation and analysis of the results of DR in smart microgrids are discussed. In this study, the real data set is used collected from Ekbatan complex. In Table 1, the maximum power of home appliances is shown. This data is recorded by Owl USB CM160 energy monitor, which is shown in Figure 5.

Table 1. Power consumption of home appliances

\begin{tabular}{|l|l|l|}
\hline No. & Appliance & Power (W) \\
\hline 1 & Washing machine & 2500 \\
\hline 2 & Dishwasher & 2000 \\
\hline 3 & Heating/cooling system & 2400 \\
\hline
\end{tabular}




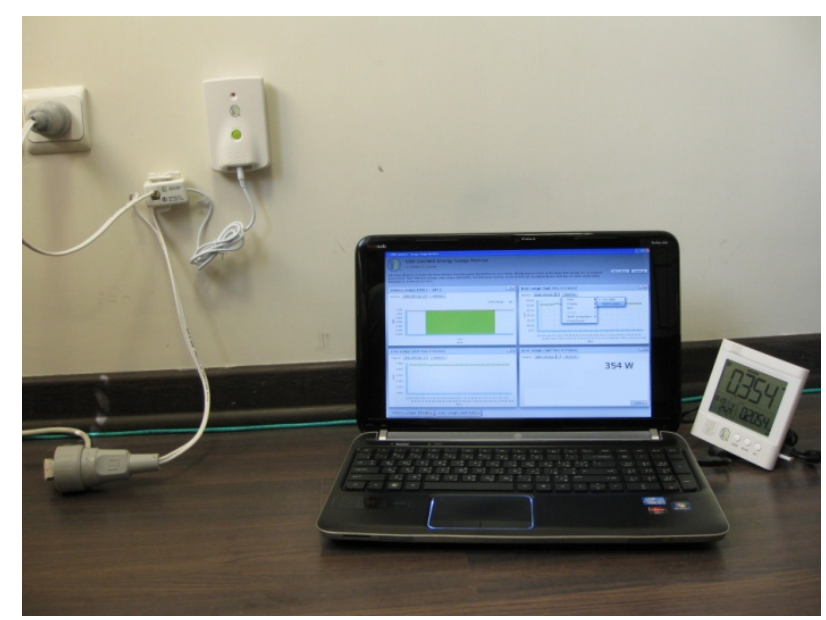

Fig. 5. The laptop power consumption measurement

\subsection{DR of washing machine}

In order to investigate the application of proposed method "DR of washing machine", the correlation between the surplus power of RE resources and the consumption power of washing machine before and after DR in smart microgrid No. 1 is determined as below.

The correlation between Psurplus and PWM unmanage is equal to 0.1 while the correlation between Psurplus and PWM manage is 0.317 . Where $\mathrm{P}_{\mathrm{WM}}$ unmanage and $\mathrm{P}_{\mathrm{WM} \text { manage }}$ are the load profile of washing machine's consumption power before and after DR implementation, respectively. The correlation between load profile of washing machine and surplus power of RE resources rises after applying the DR method. Since the consumers' comfort is assumed in the proposed method, there is no possibility for an increase in correlation amount. The maximum allowable shift at washing machines' start time is assumed to be 3 hours. The start time for the washing machine is forbidden after $10 \mathrm{pm}$.

The amount of surplus power and the load profile of washing machine before and after DR are illustrated in Figure 6.

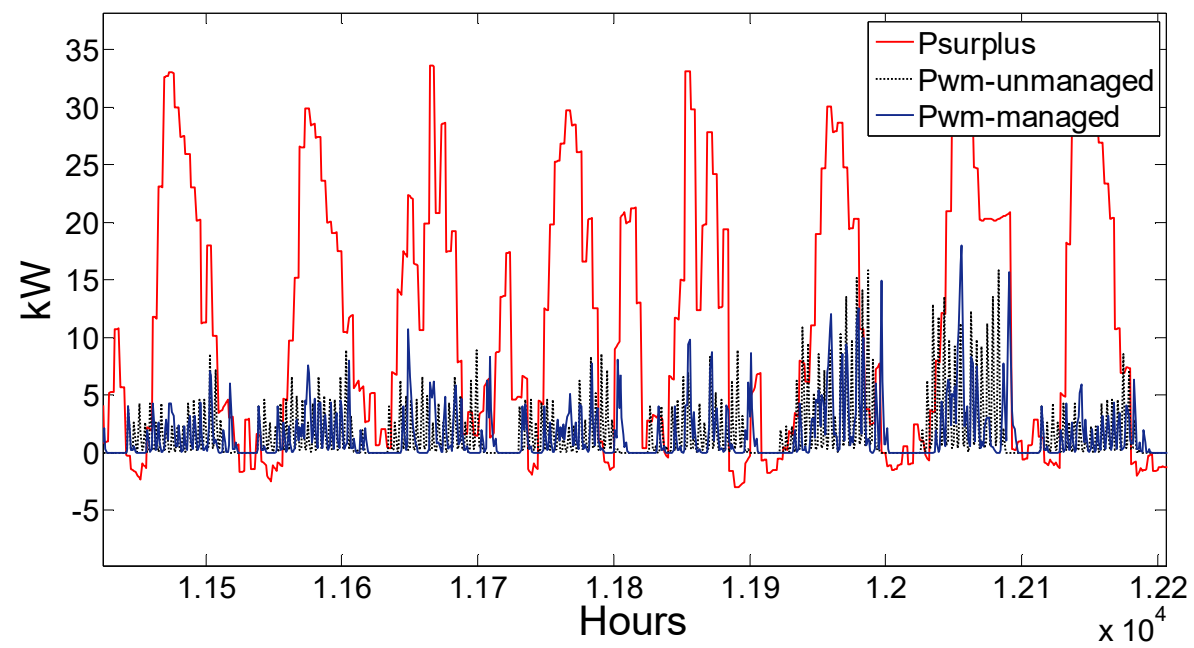

Fig. 6. The RE resources' surplus power and the load profile of washing machine before and after DR application 
As it can be seen, the consumption of washing machine becomes zero and is shifted to another time at hours when the surplus power is negative (considering the consumers' welfare). Also, the consumption in some hours is shifted to another one when more surplus power is available.

The amount of total consumption power before DR implementation is calculated as below.

$$
\begin{aligned}
& P_{\text {load-unmanage }(W M)}(t) \\
& =\mathrm{P}_{\text {base }}(\mathrm{t})+\mathrm{P}_{\mathrm{WM} \text { unmanage }}(\mathrm{t})
\end{aligned}
$$

The correlation between the total load of microgrid before and after DR application and the surplus power can be obtained as follows.

The amount of correlation between total load and surplus powers increase from 0.318 to 0.324 which proves the validity of the proposed method.

\subsection{DR of dishwasher}

In order to show the authenticity of the method like washing machines, the correlation between consumption power of washing machine before and after DR application and surplus power is equal to 0.08 and 0.39 respectively.

The behaviour of dishwasher has become more close to the surplus power of RE resources by applying DR method. It means that the method is applied correctly. The increase in correlation in the case of the dishwasher is higher than the washing machine. This can be for below reasons. The maximum allowable delay for the dishwasher is 6 hours (3 hours more than washing machine), which gives more flexibility to follow the surplus power of RE resources.

The amount of REs' surplus power and consumption power of washing machine before and after DR application are depicted in Figure 7.

According to Figure 4, if the surplus power is negative, the consumption of washing machine will be shifted to other hours (considering consumers' comfort). The consumption is shifted to hours when more surplus power is available, too. It shows that controlling dishwashers can improve the flexibility of RE resources.

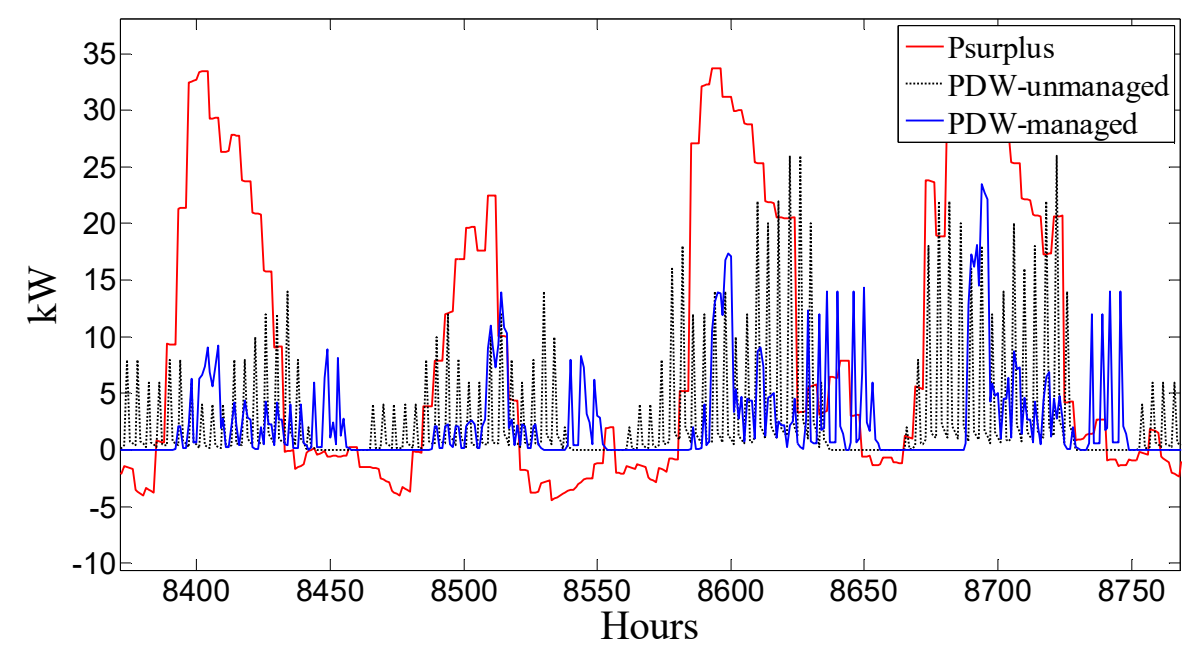

Fig. 7. The RE resources' surplus power and the load profile of dishwasher before and after DR application 
The correlation between total load before and after washing machine and dish washer's consumption management and surplus power is equal to 0.327 and 0.344 respectively.

The correlation between surplus power and total load has risen, which proves the correctness of the proposed method.

\subsection{DR of heating/cooling system}

The object of consumption management in heating/cooling system is reaching to coincidence between consumption and the surplus power of RE resources, which is done by changing the indoor temperature in acceptable range.

In order to test the application of this method, the correlation between the surplus power of RE resources and consumption power of cooling system before and after implementation is calculated 0.49 and 0.78 respectively.

Where $\mathrm{P}_{\text {Cooler unmanaged }}$ and $\mathrm{P}_{\text {Cooler managed }}$ are the consumption power of cooling system before and after DR. As it is obvious, the correlation between surplus power and cooling system grows notably. Since the consumers' welfare is assumed in this method, the correlation can't be higher than this quantity. The limitations related to users' comfort are the minimum and maximum acceptable temperature without any disturbance for consumers' comfort.

The surplus power of smart microgrid in two hot days in summer and the managed power of cooling system are illustrated in Figure 8. When the surplus power is positive, the home temperature is adjusted lower than the set temperature (considering the related constraint), so it causes a match between the behaviour of the cooling system and surplus power.

The correlation between the surplus power of RE resources and the consumption power of the heating system is equal to 0.0012 and 0.3 respectively. The correlation between load profile of heating system and surplus power increases in a condition that the proposed method is applied.

The surplus power in two cold days and the managed power of the heating system are shown in Figure 9. When the surplus power is positive, the home temperature is adjusted higher than the set temperature, which makes a coincidence between the behaviors of heating system consumption with surplus power.

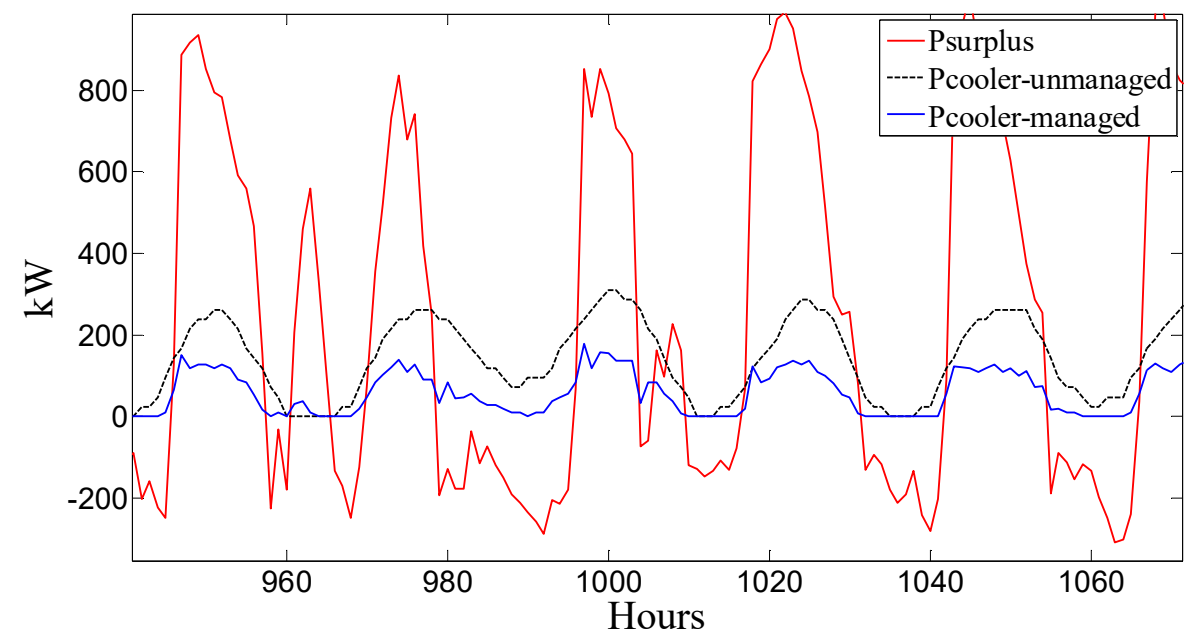

Fig. 8. The surplus power of smart microgrid in two hot days in summer, the managed and unmanaged power of cooling system 


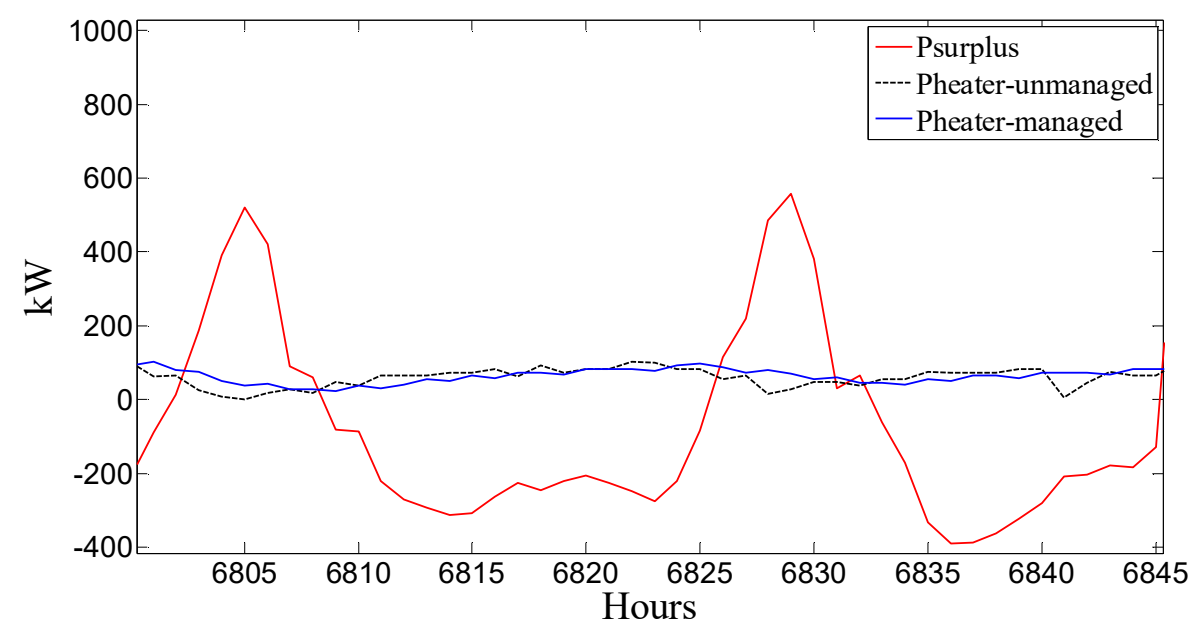

Fig. 9. The surplus power in two cold days and the managed power of the heating system

The total load of microgrid without load management of washing machine, dishwasher, and heating/cooling system can be obtained as below.

$$
\begin{gathered}
P_{\text {load-unmanage }(W M, D W, H V A C)}(t) \\
=P_{\text {load-unmanage }(W M, D W)} \\
+\mathrm{P}_{\text {HVAC unmanage }}(\mathrm{t})
\end{gathered}
$$

The correlation between total load before and after DR of washing machine, dishwasher, and heating/cooling system is equal to 0.267 and 0.447 .

The validity of proposed method is indicated in above equations with an increase in correlation.

\section{Conclusion}

This paper proposed a novel method for DR for residential controllable loads in the case of high RE penetration. The results show that applying this method increases the correlation between load consumption and the surplus RE power, i.e. this method provides the optimal use of RE resources. Since the studied microgrid is considered with a high share of RE resources, the flexibility is low in power generation, and it can't follow the load pattern. Hence, the suggested DR method can improve the flexibility of controlled loads, which compensate the low flexibility in the generation side. In the current paper, the method was employed on the smart washing machine, smart dishwasher, smart cooling/heating system, and the results were verified in all cases.

\section{Acknowledgment}

S.M. Hakimi would like to thank the research council of Islamic Azad University, Damavand, Iran for financial support of this research project. The work of M. Shafie-khah was carried out in SolarX research project with financial support provided 
by the Business Finland, 2019-2021 (grant No. 6844/31/2018). J.P.S. Catalão acknowledges the support by FEDER funds through COMPETE 2020 and by Portuguese funds through FCT, under 02/SAICT/2017 (POCI-01-0145-FEDER-029803).

\section{References}

[1] S. Kakran, S. Chanana. (2018, Jan.). Smart operations of SGs integrated with distributed generation: A review. Renewable and Sustainable Energy Reviews. [Online]. 81(3), pp. 524-535. Available: https://www.sciencedirect.com/science/article/pii/S1364032117311188

[2] G.R. Aghajani, H.A. Shayanfar, H. Shayeghi. (2017, May). Demand side management in a smart micro-grid in the presence of renewable generation and DR. Energy. [Online]. 126(1), pp. 622-637. Available: https://www.sciencedirect.com/science/article/pii/S0360544217304139.

[3] M. McPherson, B. Karney. (2017, Nov.). A scenario based approach to designing electricity grids with high variable RE penetrations in Ontario. Development and application of the SILVER model. Energy. [Online]. 138(1), pp. 185-196. Available: https://www.sciencedirect.com/science/article/pii/S0360544217312021

[4] S.M. Hakimi, S. M. Moghaddas-Tafreshi. (2012,Nov.) Effect of plug-in hybrid electric vehicles charging/discharging management on planning of smart microgrid. Journal of renewable and sustainable energy. [Online]. 4(6), pp. 063144. Available: https://aip.scitation.org/doi/full/10.1063/1.4772634.

[5] S.M. Hakimi, S. M. Moghaddas-Tafreshi. (2012,July) Optimization of smart microgrid considering domestic flexible loads. Journal of renewable and sustainable energy. [Online]. 4(4), pp. 042702. Available: https://aip.scitation.org/doi/full/10.1063/1.4772634.

[6] H. Kondziella, T. Bruckner. (2016, Jan.) Flexibility requirements of RE based electricity systems- a review of research results and methodologies. Renewable and sustainable energy reviews. [Online]. 53, pp. 10-22. Available: https://www.sciencedirect.com/science/article/pii/S1364032115008643

[7] S. Kwon. Y. Xu. N. Gautam. (2015, Nov.). Meeting inelastic demand in systems with storage and renewable sources. IEEE transactions on SG. [Online]. 8(4), pp. 1619-1629. Available: https://ieeexplore.ieee.org/document/7322282/

[8] S. Tsai. Y. Tseng. T. Chang. (2017, May.). Communication-efficient distributed DR: A randomized ADMM approach. IEEE transactions on SG. [Online]. 8(3), pp. 1085-1095. Available: https://ieeexplore.ieee.org/document/7274768/.

[9] P. Chaudhary. M. Rizwan. (2018, April). Energy management supporting high penetration of solar photovoltaic generation for SG using solar forecasts and pumped hydro storage system. RE. [Online]. 118, pp. 928-946. Available: https://www.sciencedirect.com/science/article/pii/S0960148117310911

[10] G. Papaefthymiou. K. Dragoon. (2016, May). Towards 100\% RE systems: Uncapping power system flexibility. Energy Policy. [Online]. 92, pp. 69-82. Available: https://www.sciencedirect.com/science/article/pii/S0301421516300271. 
[11] O. Erdinc. N. G. Paterakis. T. D. P. Mendes. A. G. Bakirtzis. J. P. S. Catalao. (2015, May) Smart household operation considering bi-directional EV and ESS utilization by real-time pricing based DR. IEEE transactions on SG. [Online]. 6(3), pp. 1281-1291. Available: https://ieeexplore.ieee.org/document/6901266/

[12] M. Muratori. G. Rizzoni. (2016, March). Residential DR: dynamic energy management and time-varying electricity pricing. IEEE transactions on power systems. [Online]. 31(2), pp. 1108-1117. Available: https://ieeexplore.ieee.org/document/7079509/

[13] G. Graditi, M. L. D. Silvestre. R. Gallea. E. R. Sanseverino. (2014, June). Heuristic-based shiftable loads optimal management in smart micro-grids. IEEE transactions on industrial informatics. [Online]. 11(1), pp. 271-280. Available: https://ieeexplore.ieee.org/document/6834796/

[14] J. Kennedy. P. Ciufo. A. Agalgaonkar. (2016, May). Areview of protection systems for distrbution networks embedded with renewable generation. Renewable and sustainable energy reviews. [Online]. 58, pp. 1308-1317. Available: https://www.sciencedirect.com/science/article/pii/S136403211501641X

[15]P. T. Manditereza. R. Bansal. (2016, May). Renewable distributed generation: the hidden challenges- a review from the protection perspective. Renewable and sustainable energy reviews. [Online]. 58, pp. 1457-1465. Available: https://www.sciencedirect.com/science/article/pii/S1364032115016597

[16] S. Vyas. R. Kumar. R. Kavasseri. (2017, March). Data analytics and computational methods for anti-islanding of RE based distributed generators in power grids. Renewable and sustainable energy reviews. [Online]. 69, pp. 493-502. Available: https://www.sciencedirect.com/science/article/pii/S1364032116308346

[17] S. Nan. M. Zhou. G. Li. (2018, Jan.). Optimal residential community DR sheduling in SG. Applied Energy. [Online]. 210, pp. 1280-1289. Available: https://www.sciencedirect.com/science/article/pii/S030626191730819X

[18]P. Alvina. X. Bai. Y. Chang. D. Liang. K. Lee. (2017. Dec.). Smart community based solution for energy management an experimental setup for encouraging residential and commercial consumers participation in DR program. Energy Procedia. [Online]. 143, pp. 635-640. Available: https://www.sciencedirect.com/science/article/pii/S030626191730819X

[19] R. S. Liu. Y. F. Hsu. (2018, April). Ascalable and robust approach to demand side management for SGs with uncertain renewable power generation and bi-directional energy trading. International Journal of Electrical Power \& Energy Systems. [Online]. 97, pp. 396-407. Available: https://www.sciencedirect.com/science/article/pii/S0142061517315995

[20] S. S. Reddy. (2017, March). Multi-objective based congestion management using generation resheduling and load shedding. IEEE Transactions on Power Systems. [Online]. 32(2), pp. 852-863. Available: https://ieeexplore.ieee.org/document/7475912/

[21] S. S. Reddy. (2017, Feb.). Optimal sheduling of thermal-wind-solar power system with storage. RE. [Online]. 101, pp. 13571368. Available: h https://www.sciencedirect.com/science/article/pii/S0960148116308874 
[22] Y. Zeng. D. Wang. R. Zhang. Y. Mu. H. Jia. (2017, Dec.). A new DR algorithm to maximize RE usage for grid-connected microgrid. Energy $\quad$ Procedia. [Online]. 142, pp. 2120-2125. Available: https:/www.sciencedirect.com/science/article/pii/S1876610217363737

[23]L. Park. Y. Jang. S. Cho. J. Kim. (2017, May). Residential DR for RE resources in SG systems. IEEE Transactions on Industrial Informatics. [Online]. 13(6), pp. 3165-3173. Available: https://ieeexplore.iee.org/document/7927719/

[24] J. Yang. J. Liu. Z. Fang. W. Liu. (2018, Apr.). Electricity sheduling strategy for home energy management system with RE and battery storage: a case study. IET. [Online]. 12(6), pp. 639-648. Available: https://ieeexplore.ieee.org/abstract/document/8337990/

[25] A. Vijay and A. Hawkes. (2019, Aug.). Demand side flexibility from residential heating to absorb surplus renewables in low carbon futures. Renewable Energy. [online]. 138, pp. 598-609. Available: https:/www.sciencedirect.com/science/article/abs/pii/S0960148119301259

[26]H. Wang and J. Huang. (2017, Mar.). Joint Investment and Operation of Microgrid. IEEE transactions on smart grid. [online]. 8(2), pp. 833-845. Available: https://ieeexplore.ieee.org/document/7348686

[27] J. Feng. B. Zeng. D. Zhao. G. Wu. Z. Liu. J. Zhang. (2017, Sep.). Evaluating DR impacts on capacity credit of renewable distributed generation in smart distribution systems. IEEE Access. [Online]. 6, pp. 14307-14317. Available: https://ieeexplore.ieee.org/document/8031328/

[28] J. Soares. B. Canizes. M. A. Fotouhi. Z. Vale. G. K. Venayagamoorthy. (2017, Dec.). Two-stage stochastic model using benders' decomposition for large-scale energy resource management in SGs. IEEE Transactions on Industry Applications . [Online]. 53(6), pp. 5905-5914. Available: https://ieeexplore.ieee.org/document/7968492/

[29] H. N. T. Ngyuen. C. Zhang. J. Zhang. (2016, Jan.). Dynamic demand control of electric vehicles to support power grid with high penetration level of RE. IEEE Transactions on Transportation Electrification . [Online]. 2(1), pp. 66-75. Available: https://ieeexplore.ieee.org/document/7386693/?tp=\&arnumber=7386693

[30] X. Luo. C. K. Lee. W. M. Ng. S. Yan. B. Chaudhuri. S. Y. R. Hui. (2017, May). Use of adaptive thermal storage system as smart load for voltage control and DR. IEEE Transactions on SG. [Online]. 8(3), pp. 1231-1241. Available: https://ieeexplore.ieee.org/document/7383318.

[31] Y. Liu, C. Yuen, N. U. Hassan, S. Huang, R. Yu and S. Xie. (2015, Apr.). Electricity Cost Minimization for a Microgrid With Distributed Energy Resource Under Different Information Availability. IEEE transactions on Industrial Electronics. [Online] 62(4), pp. 2571-2583. Available: https://ieeexplore.ieee.org/abstract/document/6963416.

[32] Y. Liu, C. Yuen, S. Huang, N. U. Hassan, X. Wang and S. Xie. (2014, Dec.). Peak-to-Average Ratio Constrained DemandSide Management with Consumer's Preference in Residential Smart Grid. IEEE Journal of Selected Topics in Signal Processing. [Online] 8(6), pp. 1084-1097, 2014. Available: https://ieeexplore.ieee.org/document/6840951. 
[33] W. Tushar, C. Yuen, B. Chai, S. Huang, K. L. Wood, S. G. Kerk and Z. Yang. (2016, Dec.). Smart Grid Testbed for Demand Focused Energy Management in End User Environments. IEEE wireless Communications. [Online] 23(6), pp. 70-80. Available: https://ieeexplore.ieee.org/document/7593427.

[34] W.-T. Li, C. Yuen, N. U. Hassan, W. Tushar, C.-K. Wen, K. L. Wood and K. Hu. (2015, Nov.). Demand Response Management for Residential Smart Grid: From Theory to Practice. IEEE Access. [Online] 3, pp. 2431-2440. Available: https://ieeexplore.ieee.org/document/7336481.

[35] A. Naeem, A. Shabbir, N. U. Hassan, C. Yuen, A. Ahmad and W. Tushar (2015, Dec.) Understanding Customer Behavior in Multi-Tier Demand Response Management Program. IEEE Access. [Online] 3, pp. 2613-2625. Available: https://ieeexplore.ieee.org/document/7350111.

[36] S. K. Viswanath, C. Yuen, W. Tushar, W.-T. Li, C.-K. Wen and K. Hu. (2016, Oct.) System design of the internet of things for residential smart grid. IEEE wireless communications. [Online]. 23(5), pp. 90-98. Available: https://ieeexplore.ieee.org/document/7721747.

[37] N. U. Hassan, Y. I. Khalid, C. Yuen and W. Tushar. (2015, Nov.) Customer Engagement Plans for Peak Load Reduction in Residential Smart Grids. IEEE Transactions on Smart Grid. [Online] 6(6), pp. 3029-3041, 2015. Available: https://ieeexplore.ieee.org/abstract/document/7055261.

[38] Probability methods subcommittee. (1979, Nov.). IEEE reliability test system. IEEE transactions on power apparatus and systems. [Online]. PAS-98(6), pp. 2047-2054. Available: https://ieeexplore.ieee.org/document/4113721.

[39] E. Sreeraj, K. Chatterjee and S. Bandyopadhyay. (2010, July). Design of isolated renewable hybrid power systems. Solar $\begin{array}{lllll}\text { energy. } & \text { [Online]. } & \text { 84, } & \text { 1124-1136. }\end{array}$ https://www.sciencedirect.com/science/article/abs/pii/S0038092X10001210. 